\title{
Synthesis of functionalized imidazo[4,5-e]thiazolo[3,2-b]tri- azines by condensation of imidazo[4,5-e]triazinethiones with DMAD or DEAD and rearrangement to imidazo[4,5-e]thiazolo[2,3-c]triazines
}

\author{
Alexei N. Izmest'ev ${ }^{1,2}$, Dmitry B. Vinogradov ${ }^{1}$, Natalya G. Kolotyrkina', \\ Angelina N. Kravchenko ${ }^{1,3}$ and Galina A. Gazieva*1
}

\section{Full Research Paper}

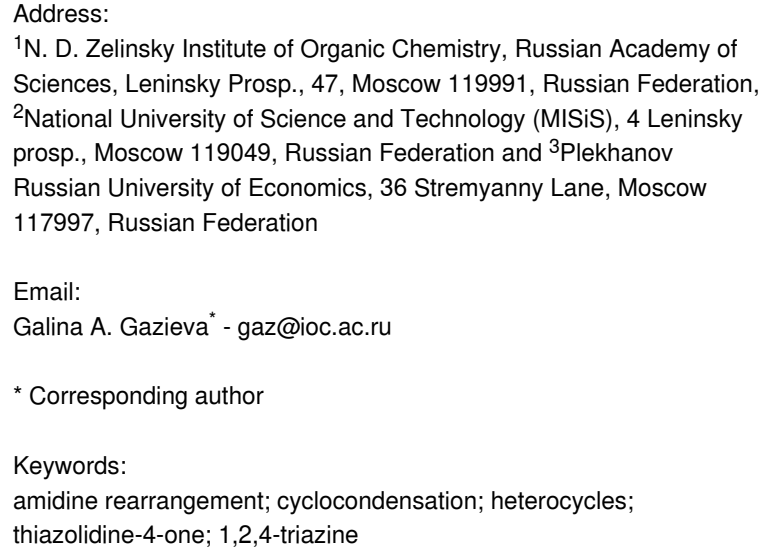

${ }^{1}$ N. D. Zelinsky Institute of Organic Chemistry, Russian Academy of Sciences, Leninsky Prosp., 47, Moscow 119991, Russian Federation, ${ }^{2}$ National University of Science and Technology (MISiS), 4 Leninsky prosp., Moscow 119049, Russian Federation and ${ }^{3}$ Plekhanov Russian University of Economics, 36 Stremyanny Lane, Moscow 117997, Russian Federation

\author{
Beilstein J. Org. Chem. 2021, 17, 1141-1148. \\ https://doi.org/10.3762/bjoc.17.87 \\ Received: 23 March 2021 \\ Accepted: 06 May 2021 \\ Published: 14 May 2021 \\ Associate Editor: B. Nay \\ (C) 2021 Izmest'ev et al.; licensee Beilstein-Institut. \\ License and terms: see end of document.
}

\begin{abstract} triazine derivatives.

\section{Introduction}

The thiazolidin-4-one heterocyclic system is a well-known, accessible and, as a consequence, a widely used pharmacophore in the chemistry of biologically active compounds possessing antimicrobial [1], antituberculosis [2], anti-inflammatory [3,4], anticancer [5], antidiabetic [6,7], and antiviral activities [8].
\end{abstract}

Two series of functionalized imidazothiazolotriazine derivatives were synthesized via the condensation of imidazo[4,5-e]-1,2,4triazine-3-thiones with acetylenedicarboxylic acid dimethyl and diethyl esters (DMAD and DEAD) and subsequent base-catalyzed rearrangement of the obtained imidazo[4,5-e]thiazolo[3,2-b]-1,2,4-triazines into regioisomeric imidazo[4,5-e]thiazolo[2,3-c]-1,2,4-

A significant number of biologically active thiazolidines amount to their heteroannelated derivatives, namely, condensed thiazolo[3,2-a]pyrimidines [9] and thiazolo[3,2-b]-1,2,4-triazoles [10], as well as related thiazolo[3,2-b]-1,2,4-triazines and thiazolo[2,3-c]-1,2,4-triazines possessing antimicrobial, antidepressant, anti-HIV, and anticancer activities [10-15]. Modifications of the position 5 of the thiazolidine cycle often lead to an enhancement of the pharmacological properties of the resulting products, which have received considerable attention in reviews $[16,17]$. The structures of some of the thiazolidine derivatives and their biological properties are specified in Figure 1. 


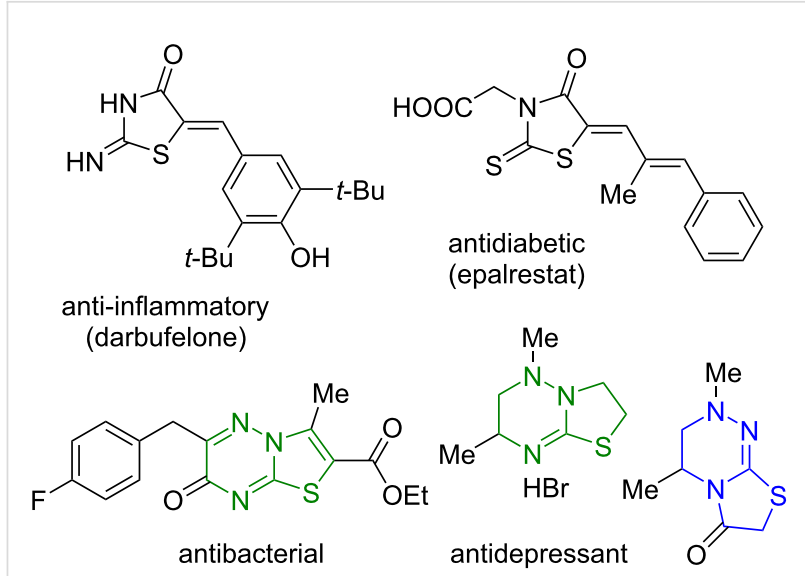

Figure 1: Biologically active compounds having thiazolidin-4-one and thiazolo-1,2,4-triazine units.

One of the effective approaches to the preparation of heteroannelated thiazolidin-4-one derivatives consists in the condensation of acetylenedicarboxylic acid esters with heterocyclic compounds containing a thiourea fragment, e.g., pyrimidinethiones [18,19], 1,2,4-triazolethiols [20], and 1,2,4-triazinethiones $[21,22]$. An important feature of the reactions of dialkyl acetylenedicarboxylates with asymmetric substrates is the high regioselectivity of the cyclizations of intermediate Michael adducts at one of several reactive nitrogen atoms. For example, reported by Giannola et al. [21], the reaction of 3-thioxo-1,2,4triazin-5-ones 1 with dimethyl acetylenedicarboxylate (DMAD) leads to the only products, namely, thiazolo[3,2-b]-1,2,4triazines 2 (Scheme 1) while the regioisomeric thiazolo[2,3-c]1,2,4-triazine derivatives remain unavailable.
The present work is devoted to the development of methods for the regiodirected synthesis of two series of functionalized imidazothiazolotriazines based on the sequential condensation of imidazo[4,5-e]-1,2,4-triazine-3-thiones 3 with DMAD or $\mathrm{DEAD}$ and skeletal rearrangement of linear imidazo[4,5-e]thiazolo[3,2-b]-1,2,4-triazines 4 into isomeric imidazo[4,5-e]thiazolo[2,3-c]-1,2,4-triazines 5 having an angular structure.

\section{Results and Discussion}

We started by examining the regioselectivity of the condensation of imidazo[4,5-e]triazine-3-thiones 3 with DEAD. The effects of temperature, the nature of the solvent, and the structure of the starting substrates on the total yields and ratios of isomeric products $\mathbf{4}$ and $\mathbf{5}$ were investigated (Table 1, see also Supporting Information File 1 for details).

The reaction of 5,7-dimethylimidazo[4,5-e]triazine-3-thione (3a) with DEAD proceeded in alcohols with moderate regioselectivity and isomer 5 predominated in the filtered precipitates (Table 1, entries 1-3). The use of absolute or $95 \%$ ethanol as a solvent did not significantly affect the total yields of isomers 4 and $\mathbf{5}$ and their ratio, while carrying out the reaction in acetic acid, as expected $[13,23,24]$, led to a change in regioselectivity and the formation of linear isomer $\mathbf{4}$ as the main product (Table 1, entries 4-6).

5,7-Diethylimidazo[4,5-e]triazine-3-thione (3b) reacted with DEAD in a similar manner (Table 1, entries 7 and 8), but with less selectivity. Substrates $\mathbf{3}$ bearing phenyl substituents at the different positions, vice versa, reacted with DEAD with high selectivity to form imidazo[4,5-e]thiazolo[3,2-b]triazines $\mathbf{4}$ as

A) previous work

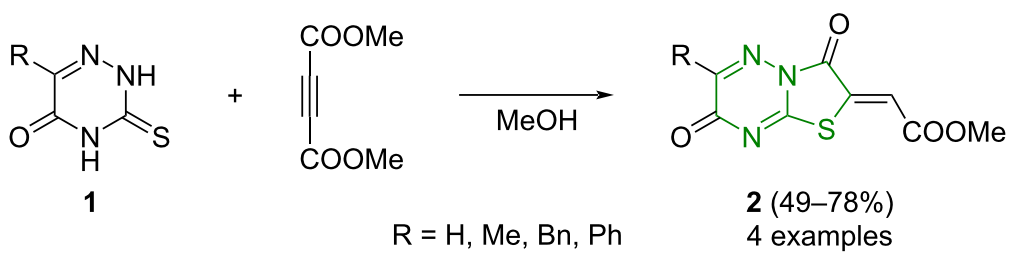

B) this work

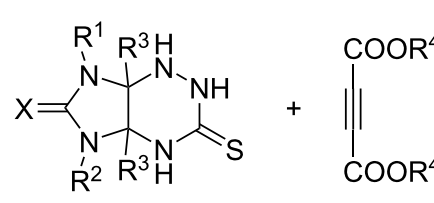

3

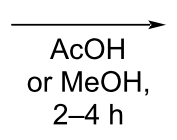

$2-4 \mathrm{~h}$<smiles>[R]OC(=O)/C=c1\sc2n(c1=O)NC1([R])N([R])C([X])N([R])C1([R])N=2</smiles>

$4(47-92 \%)$

14 examples

$X=O, S ; R^{1}=$ Me, Et; $R^{2}=$ Me, Et, Ph; $R^{3}=H, P h ; R^{4}=$ Me, Et 
Table 1: Results for the screening of the reaction conditions ${ }^{a}$.<smiles>[R1]C1=C([Y])C2([R])NC(=S)NNC2([R17])N1[R]</smiles>

3

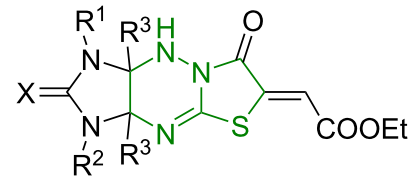

4

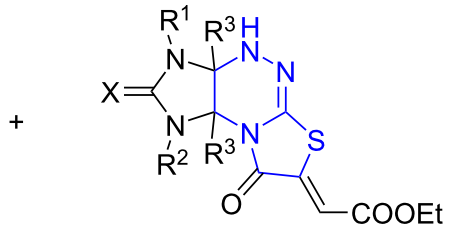

5

\begin{tabular}{|c|c|c|c|c|c|c|}
\hline entry & compound 3 & $X, R^{1}, R^{2}, R^{3}$ & conditions & $\begin{array}{l}\text { ratio of } \\
4 \text { and } 5\end{array}$ & $\begin{array}{l}\text { total yield of } \\
4+5[\%]\end{array}$ & $\begin{array}{l}\text { yield of } 4 \\
{[\%]^{\mathrm{b}}}\end{array}$ \\
\hline 1 & $3 a$ & $X=O, R^{1}=R^{2}=M e, R^{3}=H$ & $\mathrm{MeOH}$, reflux, $2 \mathrm{~h}$ & $38: 62$ & 80 & $-^{c}$ \\
\hline 2 & & & $95 \% \mathrm{EtOH}$, reflux, $2 \mathrm{~h}$ & $30: 70$ & 72 & $-^{c}$ \\
\hline 3 & & & Anh. EtOH, reflux, $2 \mathrm{~h}$ & $32: 68$ & 71 & $-^{c}$ \\
\hline 4 & & & $\mathrm{AcOH}, 50^{\circ} \mathrm{C}, 2 \mathrm{~h}$ & $83: 17$ & 72 & $-^{c}$ \\
\hline 5 & & & $\mathrm{AcOH}, 40^{\circ} \mathrm{C}, 2 \mathrm{~h}$ & $84: 16$ & 79 & 45 \\
\hline 6 & & & $\mathrm{AcOH}, 20^{\circ} \mathrm{C}, 2 \mathrm{~h}$ & $91: 9$ & 80 & 53 \\
\hline 7 & $3 b$ & $X=O, R^{1}=R^{2}=E t, R^{3}=H$ & $\mathrm{MeOH}$, reflux, $2 \mathrm{~h}$ & $54: 46$ & 68 & $-c$ \\
\hline 8 & & & $\mathrm{AcOH}, 20^{\circ} \mathrm{C}, 2 \mathrm{~h}$ & $66: 34$ & 71 & 47 \\
\hline 9 & $3 c$ & $X=O, R^{1}=R^{2}=M e, R^{3}=P h$ & $\mathrm{MeOH}$, reflux, $2 \mathrm{~h}$ & $97: 3$ & 81 & 79 \\
\hline 10 & & & $95 \% \mathrm{EtOH}$, reflux, $2 \mathrm{~h}$ & $100: 0$ & 68 & 68 \\
\hline 11 & 3d & $X=O, R^{1}=M e, R^{2}=P h, R^{3}=H$ & $\mathrm{MeOH}$, reflux, $2 \mathrm{~h}$ & $77: 23$ & 48 & $-^{c}$ \\
\hline 12 & & & $\mathrm{AcOH}, 20^{\circ} \mathrm{C}, 2 \mathrm{~h}$ & $100: 0$ & 64 & $64^{d}$ \\
\hline 13 & & & $\mathrm{AcOH}, 20^{\circ} \mathrm{C}, 4 \mathrm{~h}$ & $100: 0$ & 86 & 86 \\
\hline 14 & $3 f$ & $X=S, R^{1}=M e, R^{2}=P h, R^{3}=H$ & $\mathrm{MeOH}$, reflux, $4 \mathrm{~h}$ & $100: 0$ & 52 & 52 \\
\hline 15 & & & $\mathrm{AcOH}, 20^{\circ} \mathrm{C}, 4 \mathrm{~h}$ & - & 0 & 0 \\
\hline
\end{tabular}

aReaction conditions: stirring the mixture of imidazo[4,5-e][1,2,4]triazin-3-thione 3 (2.0 mmol) and DEAD (2.1 mmol) in solvent (4 mL). ${ }^{\mathrm{b}} \mathrm{lsolated}$ yield. cPure product $\mathbf{4}$ was not isolated. dProduct $\mathbf{4 k}$ was isolated as a mixture with $\mathbf{3 d}$.

main products (Table 1, entries 9-14). The corresponding isomeric imidazo[4,5-e]thiazolo[2,3-c]triazines 5 were formed in trace amounts and were detected only in the ${ }^{1} \mathrm{H}$ NMR spectra of the evaporated reaction mixtures. The reactions of bicyclic structures $\mathbf{3 a}-\mathbf{g}$ with dimethyl acetylenedicarboxylate proceeded with similar selectivity. However, the total yields of the corresponding methyl esters were often higher.

The optimized conditions found for each group of starting substrates $3 \mathbf{a}-\mathbf{g}$ were applied to prepare a series of imidazo[4,5$e]$ thiazolo[3,2-b]triazines $\mathbf{4 a}-\mathbf{n}$ with a linear structure (Scheme 2). Precipitates of compounds $\mathbf{4 c -}-\mathbf{g}, \mathbf{j}-\mathbf{n}$ bearing phenyl substituents contained no impurities of the corresponding isomers $\mathbf{5}$, while the structures $\mathbf{4 a}, \mathbf{b}, \mathbf{h}, \mathbf{i}$ were isolated in individual form only during fractional crystallization from the reaction mixtures.

It was previously shown [24-26] that the products of aldol condensation of imidazo[4,5-e]thiazolo[3,2- $b]$ triazines with carbonyl compounds, namely, aromatic aldehydes and isatins, are capable of skeletal rearrangement of the thiazolotriazine system proceeding in methanol upon treatment with $\mathrm{KOH}$ and resulting in the corresponding isomeric imidazo[4,5-e]thiazolo[2,3$c$ triazine derivatives. In this regard, the possibility of prepearing esters 5 with an angular structure on the basis of directed isomerization of linear imidazo[4,5-e]thiazolo[3,2$b$ ]triazines $\mathbf{4 a}-\mathbf{n}$ in basic media has been studied.

Indeed, boiling ethyl ester $\mathbf{4 h}$ in methanol in the presence of 0.5 equiv of a $40 \% \mathrm{KOH}$ aqueous solution resulted in a skeletal rearrangement of the tricyclic system, which, however, was accompanied by reesterification with methanol and partial hydrolysis of the ester group. As a result, the methyl ester $5 \mathbf{a}$ was obtained in $66 \%$ yield (Scheme 3 ).

Rearrangement of 1,3-dimethyl- and 1,3-diethylimidazo[4,5$e]$ thiazolo[3,2-b]triazines $\mathbf{4 a}, \mathbf{b}, \mathbf{h}, \mathbf{i}$ upon treatment with an equivalent amount of triethylamine in corresponding alcohols proceeded without hydrolysis of ester groups and led to the formation of the corresponding regioisomeric derivatives $\mathbf{5 a}, \mathbf{b}, \mathbf{h}, \mathbf{i}$ (Scheme 4). The isomerization of imidazo[4,5-e]thiazolo[3,2$b$ ]triazines $\mathbf{4 c}-\mathbf{g}, \mathbf{j}-\mathbf{n}$ bearing phenyl groups occurred only upon 


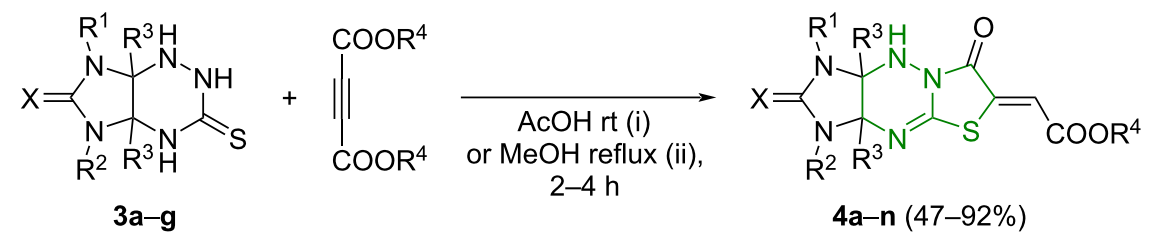

3: $X=O, R^{1}=R^{2}=M e, R^{3}=H(a) ; R^{1}=R^{2}=E t, R^{3}=H(b) ; R^{1}=R^{2}=M e, R^{3}=P h(c) ; R^{1}=M e, R^{2}=P h, R^{3}=H(d)$;

$R^{1}=E t, R^{2}=P h, R^{3}=H(e) ;$

$X=S, R^{1}=M e, R^{2}=P h, R^{3}=H(f) ; R^{1}=E t, R^{2}=P h, R^{3}=H(g)$<smiles>[R]OOC/C=c1\sc2n(c1=O)NC1C(N=2)N(C)C(=O)N1C</smiles>

4a, $R^{4}=M e, 58 \%$ (i);

4h, $R^{4}=E t, 53 \%$ (i)<smiles>[R20]OC/C=c1\sc2n(c1=O)NC1C(N=2)N(CC)C(=O)N1CC</smiles>

4b, $R^{4}=M e, 59 \%$ (i);

$4 i, \quad R^{4}=E t, 47 \%(i)$

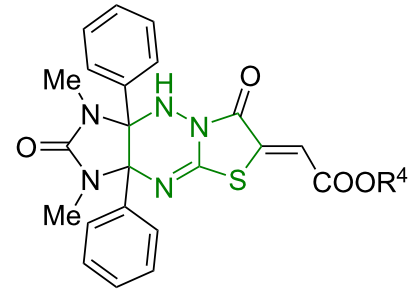

4c, $R^{4}=M e, 81 \%$ (ii);

4j, $R^{4}=E t, 81 \%$ (ii)<smiles>[R]OC=c1sc2n(c1=O)NC1C(N=2)N(c2ccccc2)C(=O)N1C</smiles>

4d, $R^{4}=\mathrm{Me}, 87 \%$ (i);

4k, $\mathrm{R}^{4}=\mathrm{Et}, 86 \%$ (i)<smiles></smiles>

4e, $R^{4}=$ Me, $92 \%$ (i);

4I, $R^{4}=E t, 79 \%$ (i)<smiles>[R]OCC=c1sc2n(c1=O)NC1C(N=2)N(c2ccccc2)C(=S)N1C</smiles>

4f, $R^{4}=M e, 65 \%$ (ii);

$4 \mathrm{~m}, \mathrm{R}^{4}=\mathrm{Et}, 52 \%$ (ii)<smiles></smiles>

4g, $\mathrm{R}^{4}=\mathrm{Me}, 54 \%$ (ii);

4n, $R^{4}=$ Et, $50 \%$ (ii)

Scheme 2: Synthesis of imidazo[4,5-e]thiazolo[3,2-b]triazine derivatives $\mathbf{4 a -} \mathbf{n}$ by the reaction of imidazo[4,5-e]triazines $\mathbf{3 a}-\mathbf{g}$ and $\mathrm{DMAD}$ or $\mathrm{DEAD}$.<smiles></smiles><smiles></smiles>

5a $(66 \%)$

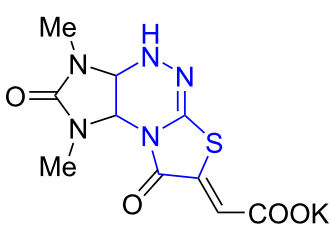

$6 a$
Scheme 3: Reaction of imidazo[4,5-e]thiazolo[3,2-b]triazine $4 \mathrm{~h}$ with aqueous $\mathrm{KOH}$. refluxing the starting compounds in corresponding alcohols in the presence of sodium alcoholates. Imidazo[4,5-e]thiazolo[2,3c]triazines 5a-n were synthesized in yields of $58-91 \%$.

Because the reaction of imidazo[4,5-e]triazines 3a,b with DMAD or DEAD led always to the formation of compounds $\mathbf{4 a}, \mathbf{b}, \mathbf{h}, \mathbf{i}$ along with their isomeric structures $\mathbf{5 a}, \mathbf{b}, \mathbf{h}, \mathbf{i}$, an attempt was made to sequentially obtain and convert the resulting mixtures of compounds $\mathbf{4}$ and $\mathbf{5}$ into the individual isomers 5 in a one-pot mode (Scheme 5).

The plausible mechanism of the formation of compounds $\mathbf{4}$ and 5 is detailed in Scheme 6. The reaction of imidazothiazolotriazines 3 with esters of acetylenedicarboxylic acid affords the Michael addition product $\mathbf{A}$, which undergoes cyclization involving the nitrogen atom N(2) to give compound 4 . Rearrangement of the latter is, probably, a result of a transamidation reac- 


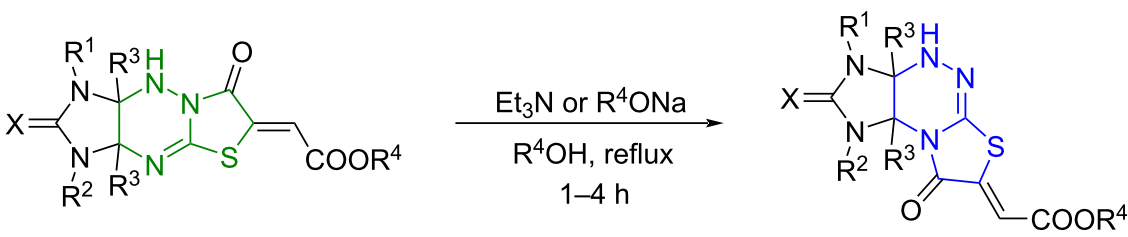

4a-n

5a-n (58-91\%)

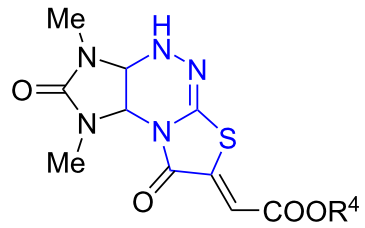

5a, $\mathrm{R}^{4}=\mathrm{Me}, 91 \%$;

5h, $\mathrm{R}^{4}=\mathrm{Et}, 80 \%$

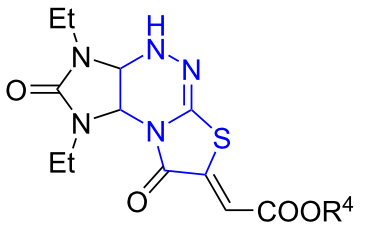

5b, $\mathrm{R}^{4}=\mathrm{Me}, 89 \%$;

5i, $R^{4}=$ Et, $76 \%$

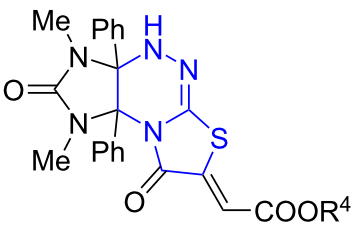

5c, $\mathrm{R}^{4}=\mathrm{Me}, 91 \%$;

5j, $R^{4}=E t, 84 \%$

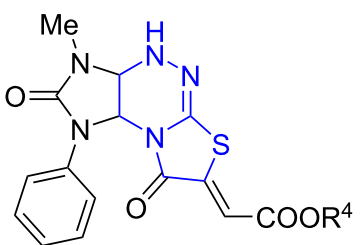

5d, $\mathrm{R}^{4}=\mathrm{Me}, 74 \%$;

5k, $\mathrm{R}^{4}=\mathrm{Et}, 81 \%$<smiles>CCOC(=O)C=c1sc2n(c1=O)C1C(NN=2)N(CC)C(=O)N1c1ccccc1</smiles>

5e, $\mathrm{R}^{4}=\mathrm{Me}, 74 \%$

5I, $R^{4}=E t, 64 \%$

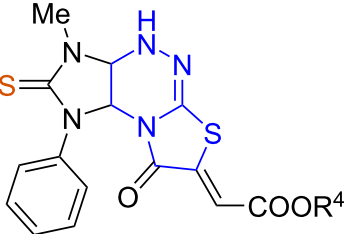

5f, $\mathrm{R}^{4}=\mathrm{Me}, 58 \%$;

$5 \mathrm{~m}, \mathrm{R}^{4}=\mathrm{Et}, 66 \%$

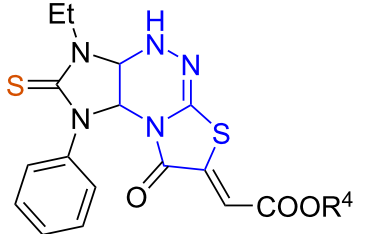

$5 \mathrm{~g}, \mathrm{R}^{4}=\mathrm{Me}, 65 \%$

$5 n, R^{4}=E t, 60 \%$

Scheme 4: Rearrangement of imidazo[4,5-e]thiazolo[3,2-b]triazines $\mathbf{4 a - n}$ into imidazo[4,5-e]thiazolo[2,3-c]triazines $\mathbf{5 a - n}$<smiles>[R1]N1C(=O)NC2NC(=S)NNC21</smiles>

$3 \mathbf{a}, \mathbf{b}$

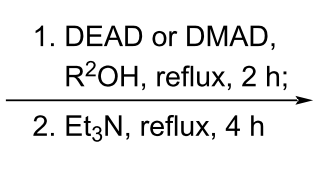

DEAD or DMAD

2. $\mathrm{Et}_{3} \mathrm{~N}$, reflux, $4 \mathrm{~h}$

5a, $R^{1}=R^{2}=M e, 83 \% ; 5 b, R^{1}=E t, R^{2}=M e, 76 \% ; 5 h, R^{1}=M e, R^{2}=E t, 62 \% ; 5 i, R^{1}=R^{2}=E t, 56 \%$

tion upon the treatment with a base, for example, alkoxide anion. The nucleophilic attack of the alkoxide anion leads to the cleavage of the $\mathrm{C}(7)-\mathrm{N}(8)$ bond to form intermediates $\mathbf{B}$ and $\mathbf{C}$ followed by the recyclization of the thiazolidine ring involving the nitrogen atom N(4) [25] to afford the product 5.

The structures of compounds $\mathbf{4} \mathbf{a}-\mathbf{n}$ and $\mathbf{5 a}-\mathbf{n}$ were elucidated by IR, ${ }^{1} \mathrm{H}$ and ${ }^{13} \mathrm{C}$ NMR, and HRMS spectral data. There are downfield shifts of the $\mathrm{NH}$ group proton signal from 6.9-7.2 to
8.0-8.4 ppm in the ${ }^{1} \mathrm{H}$ NMR spectra of angular structures 5 in comparison to the spectra of the linear isomers 4 . Downfield shifts from 4.9-5.0 for $\mathbf{4 a}, \mathbf{b}, \mathbf{h}, \mathbf{i}$ to $5.6-5.7 \mathrm{ppm}$ for $\mathbf{5 a}, \mathbf{b}, \mathbf{h}, \mathbf{i}$ and from 5.5-5.7 for $\mathbf{4 d}-\mathbf{g}, \mathbf{k}-\mathbf{n}$ to $6.3-6.5 \mathrm{ppm}$ for $\mathbf{5 d}-\mathbf{g}, \mathbf{k}-\mathbf{n}$ are also observed for the doublet of one of the bridging protons $3 \mathrm{a}-\mathrm{H}$ in compounds 4 (9a-H in compounds 5, Figure 2).

The structure of compound $\mathbf{5 i}$ was additionally confirmed by $\mathrm{X}$-ray diffraction analysis (Figure 3). 


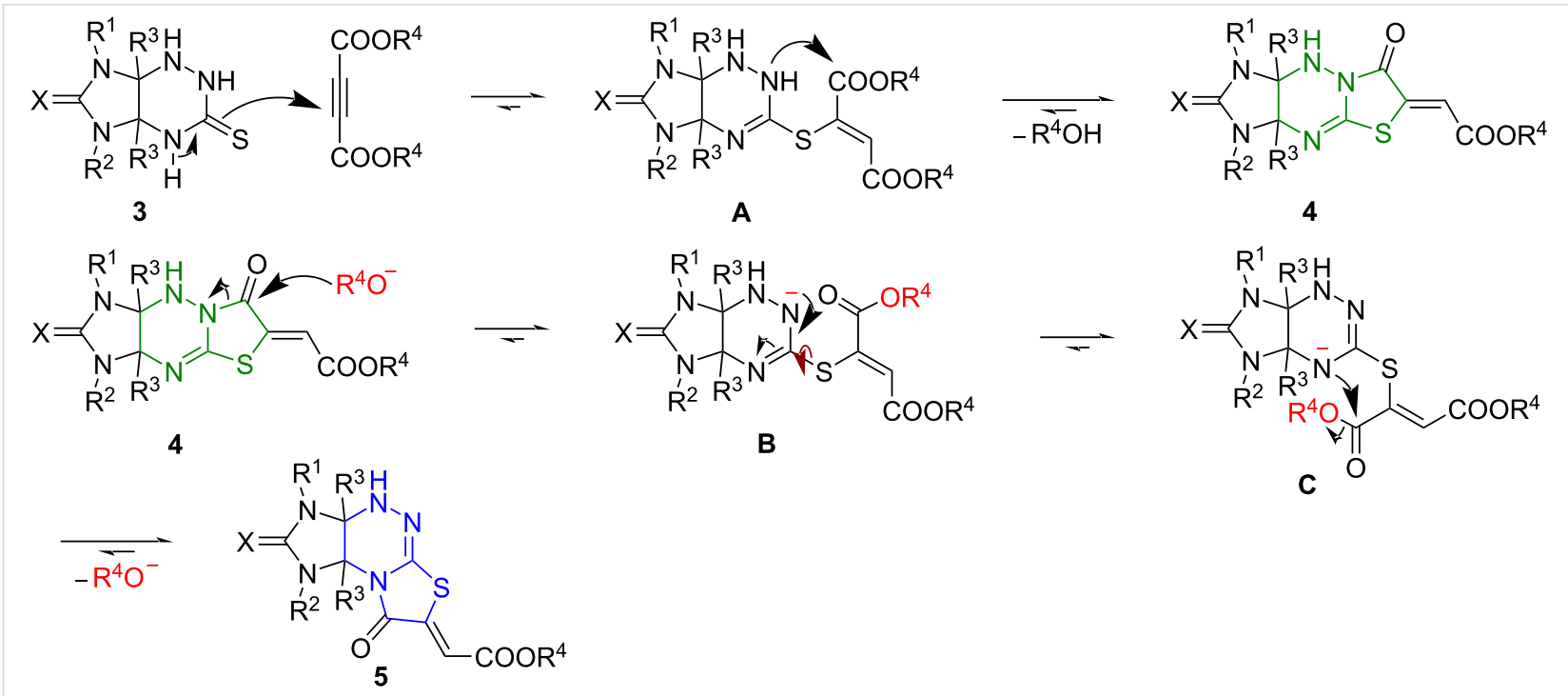

Scheme 6: Plausible mechanism of the formation and the rearrangement of compounds $\mathbf{4}$ into isomers 5 .

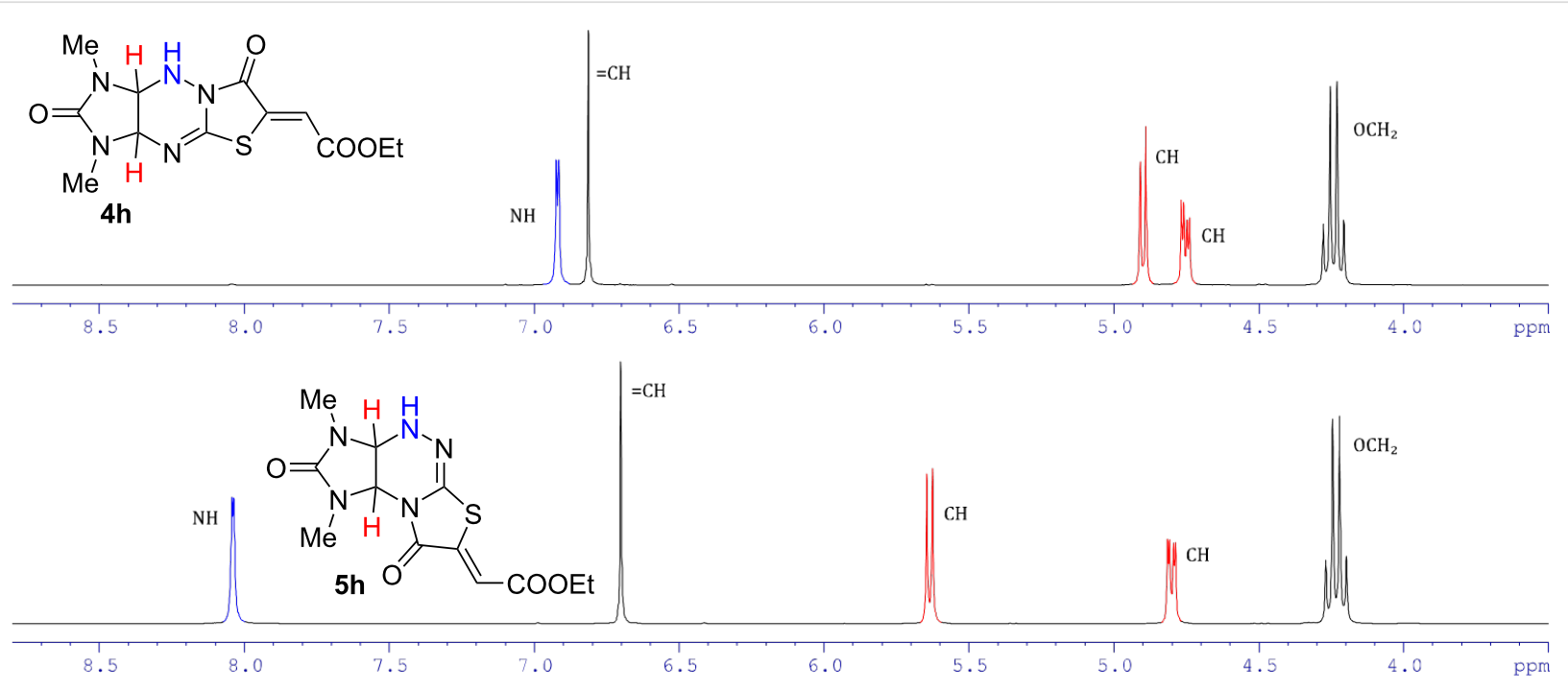

Figure 2: ${ }^{1} \mathrm{H}$ NMR spectra of compounds $4 \mathbf{h}$ and $5 \mathbf{h}$ in DMSO- $d_{6}$ in the region of 3.5-8.8 ppm.

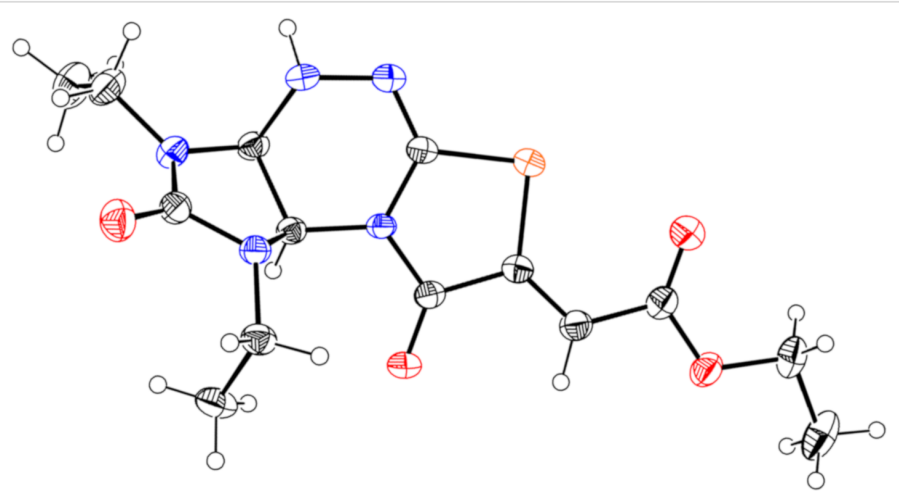

Figure 3: X-ray crystal structure of compound $\mathbf{5 i}$. 


\section{Conclusion}

Thus, the conditions for the regioselective preparation of each of the regioisomeric functionalized derivatives of imidazo[4,5$e]$ thiazolo[3,2-b]-1,2,4-triazines 4 and imidazo[4,5-e]thiazolo[2,3-c]-1,2,4-triazines 5 in an individual form were found. The methodology proved to be effective for the synthesis of a wide range of target compounds with various substituents in the tricyclic fragment. Investigations of the antiproliferative activity of the synthesized products $\mathbf{4}$ and $\mathbf{5}$, as well as possible ways of their further transformations in basic media, are continuing.

\section{Supporting Information}

\section{Supporting Information File 1}

Experimental and analytical data.

[https://www.beilstein-journals.org/bjoc/content/

supplementary/1860-5397-17-87-S1.pdf]

\section{Supporting Information File 2}

CIF file for compound $\mathbf{5 i}$.

[https://www.beilstein-journals.org/bjoc/content/

supplementary/1860-5397-17-87-S2.cif]

\section{Acknowledgements}

Crystal structure determination was performed in the Department of Structural Studies of the N. D. Zelinsky Institute of Organic Chemistry, Russian Academy of Sciences.

\section{ORCID ${ }^{\circledR} \mathrm{iDs}$}

Alexei N. Izmest'ev - https://orcid.org/0000-0003-4944-3809 Dmitry B. Vinogradov - https://orcid.org/0000-0002-5107-9383 Galina A. Gazieva - https://orcid.org/0000-0002-2248-6051

\section{References}

1. Pansare, D. N.; Mulla, N. A.; Pawar, C. D.; Shende, V. R.; Shinde, D. B. Bioorg. Med. Chem. Lett. 2014, 24, 3569-3573. doi:10.1016/j.bmcl.2014.05.051

2. Subhedar, D. D.; Shaikh, M. H.; Arkile, M. A.; Yeware, A.; Sarkar, D.; Shingate, B. B. Bioorg. Med. Chem. Lett. 2016, 26, 1704-1708. doi:10.1016/j.bmcl.2016.02.056

3. Chougala, B. M.; Samundeeswari, S.; Holiyachi, M.; Shastri, L. A.; Dodamani, S.; Jalalpure, S.; Dixit, S. R.; Joshi, S. D.; Sunagar, V. A. Eur. J. Med. Chem. 2017, 125, 101-116. doi:10.1016/j.ejmech.2016.09.021

4. Koppireddi, S.; Komsani, J. R.; Avula, S.; Pombala, S.; Vasamsetti, S.; Kotamraju, S.; Yadla, R. Eur. J. Med. Chem. 2013, 66, 305-313. doi:10.1016/j.ejmech.2013.06.005

5. Rashid, M.; Husain, A.; Shaharyar, M.; Mishra, R.; Hussain, A.; Afzal, O. Eur. J. Med. Chem. 2014, 83, 630-645. doi:10.1016/j.ejmech.2014.06.033
6. Mohammed lqbal, A. K.; Khan, A. Y.; Kalashetti, M. B.; Belavagi, N. S.; Gong, Y.-D.; Khazi, I. A. M. Eur. J. Med. Chem. 2012, 53, 308-315. doi:10.1016/j.ejmech.2012.04.015

7. Raza, S.; Srivastava, S. P.; Srivastava, D. S.; Srivastava, A. K.; Haq, W.; Katti, S. B. Eur. J. Med. Chem. 2013, 63, 611-620. doi:10.1016/j.ejmech.2013.01.054

8. Barreca, M. L.; Chimirri, A.; De Luca, L.; Monforte, A.-M.; Monforte, P.; Rao, A.; Zappalà, M.; Balzarini, J.; De Clercq, E.; Pannecouque, C.; Witvrouw, M. Bioorg. Med. Chem. Lett. 2001, 11, 1793-1796. doi:10.1016/s0960-894x(01)00304-3

9. Tozkoparan, B.; Ertan, M.; Kelicen, P.; Demirdamar, R. Farmaco 1999, 54, 588-593. doi:10.1016/s0014-827x(99)00068-3

10. Uzgören-Baran, A.; Tel, B. C.; Sarıgöl, D.; Öztürk, E. İ.; Kazkayası, İ.; Okay, G.; Ertan, M.; Tozkoparan, B. Eur. J. Med. Chem. 2012, 57, 398-406. doi:10.1016/j.ejmech.2012.07.009

11. Cai, D.; Li, T.; Xie, Q.; Yu, X.; Xu, W.; Chen, Y.; Jin, Z.; Hu, C. Molecules 2020, 25, 1307. doi:10.3390/molecules25061307

12. El-Shehry, M. F.; El-Hag, F. A. A.; Ewies, E. F. Russ. J. Org. Chem. 2020, 56, 129-136. doi:10.1134/s1070428020010200

13. Gazieva, G. A.; Izmest'ev, A. N.; Anikina, L. V.; Pukhov, S. A.; Meshchaneva, M. E.; Khakimov, D. V.; Kolotyrkina, N. G.; Kravchenko, A. N. Mol. Diversity 2018, 22, 585-599. doi:10.1007/s11030-018-9813-8

14. Izmest'ev, A. N.; Gazieva, G. A.; Kulikov, A. S.; Anikina, L. V.; Kolotyrkina, N. G.; Kravchenko, A. N. Russ. J. Org. Chem. 2017, 53, 753-763. doi:10.1134/s1070428017050177

15. Trepanier, D. L.; Krieger, P. E. Thiazolo-as-triazines. U.S. Patent US3,641,019, Feb 8, 1972.

16. Tomašić, T.; Mašič, L. P. Curr. Med. Chem. 2009, 16, 1596-1629. doi:10.2174/092986709788186200

17. Gazieva, G. A.; Izmest'ev, A. N. Chem. Heterocycl. Compd. 2015, 50, 1515-1527. doi:10.1007/s10593-014-1619-8

18. Ren, D.; Hu, X.; Li, X. Chem. Heterocycl. Compd. 2019, 55, 275-279. doi:10.1007/s10593-019-02453-1

19. Georgiev, V. S.; Bennett, G. A.; Radov, L. A.; Kamp, D. K.; Trusso, L. A. J. Heterocycl. Chem. 1986, 23, 1359-1362. doi:10.1002/jhet.5570230519

20. Fotouhi, L.; Hekmatshoar, R.; Heravi, M. M.; Sadjadi, S.; Rasmi, V. Tetrahedron Lett. 2008, 49, 6628-6630. doi:10.1016/j.tetlet.2008.09.023

21. Giannola, L. I.; Giammona, G.; Palazzo, S.; Lamartina, L. J. Chem. Soc., Perkin Trans. 1 1984, 2707-2710. doi:10.1039/p19840002707

22. Heravi, M. M.; Rahimizadeh, M.; Iravani, E.; Ghassemzadeh, M. Phosphorus, Sulfur Silicon Relat. Elem. 2003, 178, 797-802. doi:10.1080/10426500307786

23. Gazieva, G. A.; Poluboyarov, P. A.; Nelyubina, Y. V.; Struchkova, M. I. Kravchenko, A. N. Chem. Heterocycl. Compd. 2012, 48, 1382-1389. doi:10.1007/s10593-012-1147-3

24. Gazieva, G. A.; Izmest'ev, A. N.; Nelyubina, Y. V.; Kolotyrkina, N. G.; Zanin, I. E.; Kravchenko, A. N. RSC Adv. 2015, 5, 43990-44002. doi:10.1039/c5ra07669b

25. Izmest'ev, A. N.; Vasileva, D. A.; Melnikova, E. K.; Kolotyrkina, N. G.; Borisova, I. A.; Kravchenko, A. N.; Gazieva, G. A. New J. Chem. 2019, 43, 1038-1052. doi:10.1039/c8nj05058a

26. Izmest'ev, A. N.; Kim, N. A.; Karnoukhova, V. A.; Kolotyrkina, N. G.; Kravchenko, A. N.; Gazieva, G. A. ChemistrySelect 2019, 4, 10483-10487. doi:10.1002/slct.201902461 


\section{License and Terms}

This is an Open Access article under the terms of the Creative Commons Attribution License (https://creativecommons.org/licenses/by/4.0). Please note that the reuse, redistribution and reproduction in particular requires that the author(s) and source are credited and that individual graphics may be subject to special legal provisions.

The license is subject to the Beilstein Journal of Organic Chemistry terms and conditions:

(https://www.beilstein-journals.org/bjoc/terms)

The definitive version of this article is the electronic one which can be found at:

https://doi.org/10.3762/bjoc.17.87 